\title{
How much is too much? Phenotypic consequences of Rai1 overexpression in mice
}

\author{
Santhosh Girirajan ${ }^{1}$, Nisha Patel ${ }^{2,3}$, Rebecca E Slager ${ }^{4}$, Mary E Tokarz $^{5}$, Maja Bucan ${ }^{6}$, \\ Jenny L Wiley ${ }^{5}$ and Sarah H Elsea*,1,2
}

\begin{abstract}
${ }^{1}$ Department of Human Genetics, Medical College of Virginia Campus, Virginia Commonwealth University, Richmond, VA, USA; ${ }^{2}$ Department of Pediatrics, Medical College of Virginia Campus, Virginia Commonwealth University, Richmond, VA, USA; ${ }^{3}$ Faculty of Health and Life Sciences, University of the West of England, Bristol, UK; ${ }^{4}$ Department of Internal Medicine, University of Nebraska Medical Center, Omaha, NE, USA; ${ }^{5}$ Department of Pharmacology and Toxicology, Medical College of Virginia Campus, Virginia Commonwealth University, Richmond, VA, USA;

${ }^{6}$ Department of Genetics, University of Pennsylvania School of Medicine, Philadelphia, PA, USA
\end{abstract}

The retinoic acid induced 1 (RAI1) gene when deleted or mutated results in Smith-Magenis syndrome (SMS), while duplication of $17 \mathrm{p} 11.2$, including $R A I 1$, results in the dup $(17)(\mathrm{p} 11.2)$ syndrome characterized by mental retardation, growth and developmental delays, and hyperactivity. Mouse models for these human syndromes may help define critical roles for RAI1 in mammalian development and homeostasis that otherwise cannot be deduced from patient studies. A mouse model for duplication, $D p(11) 17+$, involving Rai1 has been reported. However, this mutant was engineered on a mixed genetic background confounding phenotypic effects due to possible modifier genes. We have therefore created and evaluated mice with a graded series of four (hemizygous) and six (homozygous) copies of Rai1, and overexpressing Rai1 >1.5-fold and > 2-fold, respectively. Data show that Rai1-transgenic mice have growth retardation, increased locomotor activity, and abnormal anxiety-related behavior compared to wild-type littermates. Rai1-transgenic mice also have an altered gait with short strides and long sways, impaired ability on a cagetop hang test, decreased forelimb grip strength, and a dominant social behavior. Further, analyses of homozygous transgenic mice revealed a dosage-dependent exacerbation of the phenotype, including extreme growth retardation, severe neurological deficits, and increased hyperactivity. Our results show that Rai1 dosage has major consequences on molecular processes involved in growth, development, and neurological and behavioral functions, thus providing evidence for several dosage-thresholds for phenotypic manifestations causing dup(17)(p11.2) syndrome or SMS in humans.

European Journal of Human Genetics (2008) 16, 941-954; doi:10.1038/ejhg.2008.21; published online 20 February 2008

Keywords: Rai1; dosage-threshold; BAC transgenic; dup(17)(p11.2) syndrome; Smith-Magenis syndrome; mouse model

\footnotetext{
*Correspondence: Dr SH Elsea, Departments of Pediatrics and Human Genetics, Medical College of Virginia Campus, Virginia Commonwealth University, 12-018 Sanger Hall, 1101 E Marshall Street, PO Box 980441, Richmond, VA 23298, USA.

Tel: + 1804628 0987; Fax: + 1804628 1609;

E-mail: selsea@vcu.edu

Received 12 November 2007; revised 31 December 2007; accepted 6 January 2008; published online 20 February 2008
}

Introduction

Smith-Magenis syndrome (SMS) and dup(17)(p11.2p11.2) are associated with reciprocal chromosome $17 \mathrm{p} 11.2$ rearrangements that include the retinoic acid induced 1 (RAI1) gene. ${ }^{1,2}$ SMS is characterized by mental retardation, craniofacial and skeletal abnormalities, speech and motor delays, sleep abnormalities, neurological and 
behavioral features, and obesity. ${ }^{3}$ Recently, we determined that haploinsufficiency of RAI1 is responsible for most SMS features, while other genes in the SMS region contribute to the more variable features and overall severity of the phenotype. ${ }^{2,4}$ Patients with dup(17)(p11.2) syndrome present with mental retardation, preand postnatal growth retardation, cognitive impairment, craniofacial abnormalities, heart defects, and hyperactivity. ${ }^{1,5}$ More than 40 patients with $\operatorname{dup}(17)(\mathrm{p} 11.2 \mathrm{p} 11.2)$, ranging from 1.3 to $15 \mathrm{Mb}$ in size, have been described. ${ }^{1,5}$ The critical region for the duplication has been narrowed down to approximately $1.3 \mathrm{Mb}$ and also contains $R A I 1 .{ }^{1,5}$ So, it is likely that $R A I 1$ plays a dosage-sensitive role contributing to both SMS and $\operatorname{dup}(17)(\mathrm{p} 11.2)$ syndrome.

RAI1 (GenBank AY172136, AJ271790; OMIM*607642), which maps within the SMS region, is formed by six exons generating an approximately $8.5 \mathrm{~Kb}$ mRNA and a 1906 amino-acid protein. ${ }^{6}$ The $R A I 1$ protein contains a bipartite nuclear localization signal, polyglutamine and polyserine tracts, and a PHD/zinc-finger domain at the C-terminus. While polyglutamine and polyserine stretches have been shown to be involved in transcription, ${ }^{7}$ the PHD domain in RAI1 is similar to that in the trithorax family of nuclear proteins that is involved in transcription-associated chromatin remodeling and transcriptional regulation. $^{8}$ RAI1 is highly conserved through vertebrate evolution. ${ }^{9}$ Murine Rai1 (originally described as GT1) is upregulated in P19 embryonal carcinoma cells following treatment with retinoic acid to induce neuronal differentiation. ${ }^{10}$ However, the exact functional role of RAI1 is not known.

To completely evaluate the phenotypic consequences of gene dosage for Rai1, BAC-transgenic mice containing two (hemizygous transgenic) or four (homozygous transgenic) additional copies of Rai1, were created. We tested these BAC-transgenic mice in a variety of experimental paradigms for physical, neurological, and behavioral phenotypes using a modified version of the SHIRPA (Smith Kline Beecham Pharmaceuticals, Harwell, MRC Mouse Genome Center and Mammalian Genetics Unit, Imperial College School of Medicine at St Mary's, Royal London Hospital, St Bartholomew's, and the Royal London School of Medicine Phenotypic Assessment) protocol, ${ }^{11-13}$ and a functional observational battery (F.O.B). ${ }^{14,15}$ Results indicate significant growth retardation, increased hyperactive behaviors, and impaired neurological and sensorimotor activity in Rai1 BAC-transgenic mice with a dosagedependent worsening of the phenotype with increased copies of Rai1. Our overexpression model taken together with other studies suggests that phenotypic consequences of Rai1 expression are associated with dosage thresholds for Rai1-specific biological processes, alteration of which leads to phenotypes associated with $\operatorname{dup}(17)(\mathrm{p} 11.2)$ syndrome and SMS.

\section{Materials and methods Creation of Rai1-transgenic mice}

A BAC clone, RP23-326M22 (GenBank accession AC096624), containing the entire mouse Rai1 gene, was chosen from a fully sequenced $\mathrm{C} 57 \mathrm{Bl} / 6 \mathrm{~J}$ mouse genomic library. Rai1 BAC-transgenic mice were created as a fee for service at the University of Michigan Transgenic Animal Core. After using a modified Qiagen DNA isolation protocol for low-copy plasmids (Qiagen Inc., Valencia, CA, USA), $0.5-1 \mathrm{ng} / \mu \mathrm{l}$ of purified, Not1-linearized BAC DNA was microinjected into the fertilized mouse eggs from two separate crosses: $(\mathrm{C} 57 \mathrm{Bl} / 6 \mathrm{~J} \times \mathrm{SJL}) \mathrm{F} 1$ and $(\mathrm{C} 57 \mathrm{Bl} /$ $6 \mathrm{~J} \times \mathrm{SJL}) \quad \mathrm{F} 1$ or $\mathrm{C} 57 \mathrm{Bl} / 6 \mathrm{~J} \times(\mathrm{C} 57 \mathrm{Bl} / 6 \mathrm{~J} \times \mathrm{SJL}) \mathrm{F} 1$, and eggs were transferred to recipient mothers. Three weeks following the microinjection, founder pups were born, genotyped, and later bred to $\mathrm{C} 57 \mathrm{Bl} / 6 \mathrm{~J}$ females. Two male founders, C57BL/6J-Tg(RP23-326M22)1She (line 760) and C57BL/6J-Tg(RP23-326M22)2She (line 775), showed single, intact BAC site insertion into the genome and germ-line transmission of the BAC transgene. In addition to Rai1, the BAC also contains a sterol regulatory element binding protein (Srebp1) and $3^{\prime}$ end of target of Myb-1-like-2 (Tom112). Transgenic lines were established and maintained by backcrossing to $\mathrm{C} 57 \mathrm{Bl} / 6 \mathrm{~J}$ mice for more than six generations (>99\% $\quad \mathrm{C} 57 \mathrm{Bl} / 6 \mathrm{~J}$ background). The BACtransgenic mice are named according to the International Committee on Standardized Genetic Nomenclature for Mice (www.informatics.jax.org/). Mice (lines 760 and 775), carrying four or five copies of Rai1, respectively (single site insertion of two or three BACs, respectively), are termed 'hemizygous,' and progeny of F1 crosses of 760 hemizygotes are termed 'homozygous' throughout the manuscript.

\section{Breeding and maintenance}

Rai1 transgenic male founders were bred with $\mathrm{C} 57 \mathrm{Bl} / 6 \mathrm{~J}$ female mice obtained from the JAX ${ }^{\circledR}$-mice services (The Jackson Laboratory, Bar Harbor, ME, USA). For breeding, separate cages containing a transgenic male and 1-2 $\mathrm{C} 57 \mathrm{Bl} / 6 \mathrm{~J}$ females or a transgenic female and a $\mathrm{C} 57 \mathrm{Bl} / 6 \mathrm{~J}$ male, or a transgenic male and a transgenic female were set up. The pups were genotyped, weaned, and separated based on sex at 3 weeks of age. Then, mice were housed 2-5 per cage and had access to standard diet, Prolab ${ }^{\circledR}$ RMH 2000 (PMI Nutrition International Inc., Brentwood, MO, USA) and water ad libitum. The mouse room was maintained on a $12 \mathrm{~h}: 12 \mathrm{~h}$ light:dark cycle, and all the tests, except the tests for circadian rhythm, were performed during the light phase. Ambient temperature $\left(21^{\circ} \mathrm{C}\right)$ and humidity $(40 \%)$ were maintained. Animals used in our study were cared for in accordance with the guidelines of the Institutional Animal Care and Use Committee of Virginia Commonwealth University and the Guide for the Care and Use of Laboratory Animals (National Research Council, 1996). 
Genotyping of Rai1 BAC-transgenic mice

Mice were genotyped by PCR analysis using template genomic DNA from mouse tails prepared using a standard phenol/chloroform procedure. PCR was carried out using two pairs of unique BAC-end specific primers. Primers SP6 F (5'-GATCCTCCCGAATTTCACTAGTG-3') and SP6 R (5'TCCAGACTTGCTTGTGAACG-3') were used to amplify a $450 \mathrm{bp}$ fragment unique to the SP6 end of the BAC transgene, and primers T7 F (5'-GGTCGAGCTTGACATTG TAG-3') and T7 R ( $5^{\prime}$-GGTAAGAAGTCCCCAGTCC-3') were used to amplify a $400 \mathrm{bp}$ fragment specific to the T7 end of the BAC. As a control for DNA quality and wild-type animals, $\beta$-globin primers $\mathrm{F}$ ( $5^{\prime}$-CCAATCTGCTCACACAGG ATAGAGAGGGCAGG-3') and R (5'-CCTTGAGGCTGTCCA AGTGATTCAGGCCATCG-3') were used to amplify a $500 \mathrm{bp}$ fragment. PCR was performed with $100 \mathrm{ng}$ mouse tail genomic DNA, 20 pmol each of forward and reverse primers, $10 \mathrm{~mm}$ Tris- $\mathrm{HCl}, 50 \mathrm{~mm} \mathrm{KCl}, 1.5 \mathrm{~mm} \mathrm{MgCl}_{2}$, $200 \mu \mathrm{M}$ dNTPs, and $1 \mathrm{U}$ Taq DNA polymerase in a total reaction volume of $25 \mu \mathrm{l}$. Reactions were held at $94^{\circ} \mathrm{C}$ for $5 \mathrm{~min}$ followed by 30 cycles of denaturing at $94^{\circ} \mathrm{C}, 1 \mathrm{~min}$; annealing at $60^{\circ} \mathrm{C}(\mathrm{SP} 6$ and $\mathrm{T} 7) / 59^{\circ} \mathrm{C}(\beta$-globin) for $1 \mathrm{~min}$; and an extension at $72^{\circ} \mathrm{C}, 1 \mathrm{~min}$, followed by a final extension at $72^{\circ} \mathrm{C}, 10 \mathrm{~min}$. Reactions were held at $4{ }^{\circ} \mathrm{C}$ until use. The tail DNA from Rai1-transgenic mice showed amplification with SP6, T7, and $\beta$-globin primers, while DNA from the non-transgenic mice amplified with only $\beta$-globin primers.

Copy number evaluation of Rai1 BAC-transgenic mice Southern analysis To assess the copy number of the Rai1 gene in the transgenic mice, $3.5 \mu \mathrm{g}$ of tail DNA from transgenic mouse and control DNA for the copy number standards were digested with $4 \mathrm{U}$ of HindIII. Copy number standards were prepared by spiking control mouse DNA with appropriate amounts of BAC DNA, representing 1,3 , 5 , or 10 copies of RP23-326M22, just prior to the digestion. All samples were electrophoresed in a $1 \%$ agarose gel, transferred to a nylon membrane, and hybridized to radioactive-labeled probes using standard protocols. The $3^{\prime}$ end of an Rai1 cDNA clone (IMAGE: 1211624), a purified RP23-326M22 SP6-end PCR product, and a purified T7-end PCR product were used as probes. A densitometric analysis was done, standard curve derived, and the putative copy number was obtained from the line equation of the standard curves.

Real-time PCR TaqMan ${ }^{\circledR}$ copy number determination assays were performed using genomic DNA isolated from the livers of founder mice, 760 and 775, and other mice from these lines using the DNeasy kit (Qiagen, Germantown, MD, USA). Prior to the assays, serial dilutions of genomic DNA samples (100, 10, 1, 0.1, and $0.01 \mathrm{ng})$ from a C57Bl/6J mouse were prepared and used for validation of the method. A genomic DNA sample of a known non-transgenic mouse carrying disomic copies of Rai1 was used as a calibrator. For transgene amplification, a Taqman Rai1 (D29801) primer/probe set was used (Applied Biosystems, Foster City, CA, USA). A single-copy gene, glucagon, was used as an endogenous control with the primer/probe set sequences described previously. ${ }^{16}$ All samples were run in triplicate in $20-\mu \mathrm{l}$ reactions containing $2 \times$ TaqMan Universal PCR Master Mix (Applied Biosystems), primers at a final concentration of $900 \mathrm{~nm}$ each, $250 \mathrm{~nm}$ of the probe, and $50 \mathrm{ng}$ of DNA. The PCR was run in the ABI Prism ${ }^{\circledR} 7900$ HT Sequence Detection System (Applied Biosystems) using the following amplification parameters: $10 \mathrm{~min}$ at $95^{\circ} \mathrm{C}$, and 40 cycles of $15 \mathrm{~s}$ at $95^{\circ} \mathrm{C}$ and $1 \mathrm{~min}$ at $60^{\circ} \mathrm{C}$. Delta delta $C_{\mathrm{t}}\left(2^{-\Delta \Delta C_{\mathrm{t}}}\right)$ method was used to compare the $\Delta C_{\mathrm{t}}$ (cycle threshold $\left(C_{\mathrm{t}}\right) ; C_{\mathrm{t}}$ of target $-C_{\mathrm{t}}$ of control gene) value of transgenic animal samples with unknown transgene copy numbers with the $\Delta C_{\mathrm{t}}$ of a known calibrator.

\section{Rai1 expression analysis in transgenic mice}

Reverse-transcription and quantitative real-time PCR RNA samples were prepared from brain and liver tissues collected from both transgenic and non-transgenic animals using TRIzol reagent according to the manufacturer's instructions (Invitrogen, Carlsbad, CA, USA). Prior to reverse transcription, the RNA samples were treated with DNase I according to the manufacturer's instructions (Ambion Inc., Austin, TX, USA). The possibility of contamination with genomic DNA was eliminated by using 'no $\mathrm{RT}^{\prime}$ ' controls in the reaction and also by performing a PCR using GAPDH primer sets amplifying across an intron. ${ }^{17}$ First strand cDNA synthesis was carried out with $5 \mu \mathrm{g}$ of total RNA and $1 \mu \mathrm{l}$ oligo(dT) $)_{12-18}$ $(500 \mathrm{mg} / \mathrm{ml})$ using the MMLV reverse transcriptase protocol according to the manufacturer's instructions (Invitrogen). For quantitative real-time PCR, pre-designed Rai1 Taqman primers were used (Applied Biosystems). All samples were run in triplicate in $10-\mu \mathrm{l}$ reaction volumes. PCR conditions were the default settings of the ABI Prism 7900 HT Sequence Detection System (ABI). The cycle threshold $\left(C_{t}\right)$ was determined during the geometric phase of the PCR amplification plots, as recommended by the manufacturer. Relative differences in Rai1 transcript levels were quantified using the $\Delta \Delta C_{\mathrm{t}}$ method with the glucagon mRNA as a gene loading control.

\section{Phenotypic evaluation}

All transgenic offspring were evaluated alongside their age and sex-matched non-transgenic littermates. Mice were subjected to a modified SHIRPA protocol consisting of an initial battery of tests adapted from SHIRPA, ${ }^{13}$ the Irwin observational battery, ${ }^{12}$ and the test battery described by Crawley and Paylor. ${ }^{1,18}$ All tests were performed in the same order for each mouse under appropriate behavioral testing conditions as described. For quantitative assessment 
of behavioral responses, mice were evaluated at 5, 10, and 20 weeks of age using a F.O.B. Two separate cohorts of mice were generated, one for the modified SHIRPA and the other for the F.O.B. The first cohort consisted of 35 Rai1 transgenic hemizygotes and 67 non-transgenic mice, and the second was composed of 13 Rai1 transgenic hemizygotes, 9 transgenic homozygotes, and 12 non-transgenic mice. The F.O.B. was originally described for rats, ${ }^{14}$ but was later modified for mice. ${ }^{15}$ It consists of a series of tests for noninvasive, rapid, and quantitative assessment of autonomic, sensory, and motor integrity in mice. F.O.B. experiments were conducted by an observer who was blinded to the genotypes of the mice. Detailed protocols for all the tests conducted, including circadian activity, histological and serum analyses are given in the Supplementary material. All phenotypic evaluations described are for Rai1 hemizygous transgenics unless otherwise noted.

After the physical, behavioral and neurological evaluations, the mice were euthanized and dissected for gross examination of internal organs. Major organs (brain, heart, liver, spleen, kidneys, and thymus) were sectioned for histological assessments. All reported data were generated from the 760 line; however, the 775 line of mice showed similar results (Supplementary Figure S2, Supplementary Table S1).

\section{Statistical analyses}

Statistical analyses were performed using GraphPad Prism version 4.02 for Windows (GraphPad Software, San Diego, CA, USA). All data were analyzed for both males and females from each genotype (unless otherwise noted) using unpaired Student's t-test, and one-way (genotype) or twoway (genotype $\times$ age) analysis of variance (ANOVA). Categorical data were analyzed using either Fisher's exact test or a $\chi^{2}$ test. Post hoc comparisons were made using Bonferroni's correction for multiple comparisons. The level of significance was set at $P<0.05$.

\section{Results \\ Production of Rai1 BAC-transgenic mice}

A linearized BAC clone, RP23-326M22, containing Rai1 was used for microinjection of fertilized eggs. Forty-two live pups (17 females and 25 males) were initially analyzed by PCR for the presence of both (SP6 and T7) unique ends of the BAC vector (Figure 1a), resulting in five male founder mice positive for the Rai1-BAC transgene. Two of these founder mice showed single genomic site insertion and stable transmission of the BAC and were successfully mated to establish the transgenic lines 760 and 775 . Rai1 transgenic pups were obtained from each of these lines at the expected Mendelian ratios. Similar phenotypes were observed for both lines, confirming the absence of position effects.

\section{Copy number assessment and expression profile of Rai1-transgenic mice}

The copy numbers of BAC-transgenic mice were evaluated using a semi-quantitative Southern blotting technique and confirmed by a quantitative real-time PCR assay (qPCR) using Rai1-specific Taqman probes. Southern blotting, confirmed by copy number qPCR, showed that the Rai1 transgenic founders carry approximately four copies in the 760 line and five copies in the 775 line (Figure $1 \mathrm{~b}$ and c). Homozygous transgenic mice (evaluated and discussed later) with a total of six copies of Rai1 were obtained by breeding transgenic mating pairs from the 760 line (Figure 1c). Evaluation of cDNA derived from transgenic whole brain and liver using quantitative real-time PCR showed $>50 \%$ increase in Rai1 mRNA levels in hemizygous transgenic mice (Figure 1d) and $>100 \%$ increase in homozygous transgenic mice (Supplementary Figure S1A). Expression levels were also confirmed by western blots using protein lysates from transgenic whole brain and liver (Supplementary Figure S1B).

\section{General physical assessment}

The transgenic mice were delivered at term and did not exhibit any obvious birth defects. Preliminary general physical examinations and tests for simple reflexes were conducted to identify and define the behavioral and functional profiles of Rai1-transgenic mice (Table 1). Transgenic mice demonstrated overtly active, wild running behavior during the 30-min observational period compared to the non-transgenics $(5 / 24$ for transgenics versus $1 / 51$ for non-transgenics, $P=0.01$; Fisher's exact test) (Table 1). Despite some variability between transgenics and non-transgenics, no intergroup difference emerged on any of the observations for abnormal grooming such as short/sparse whiskers (2/24 versus $3 / 51)$ and bald patches (1/24 versus $1 / 51)$, for simple reflexes such as the righting reflex, whisker response (2/24 versus 3/51), eye blink/ear twitch response, and pupillary response (Table 1$)$. Similarly, no autonomic (defecation, urination, lacrimation, and salivation) dysfunction was documented in the two groups (Table 1).

\section{Growth retardation in Rai1-transgenic mice}

The growth pattern of the transgenic line of pups along with their wild-type littermates was monitored by measuring body weights and lengths at 5, 10, 20, and 30 weeks of age. Rai1-transgenic mice weighed less than their wild-type littermates up to 20 weeks (Figure 2a). A two-way ANOVA of body weights from the 760 line of mice showed significant effect of genotype $(P<0.0001)$, age $(P<0.0001)$, and genotype $\times$ age interval interaction $(P<0.0001)$. Overall, the male transgenic mice $(P<0.05)$ were more growth retarded than the female transgenics. Furthermore, Rai1 transgenics were significantly shorter in length compared to their non-transgenic littermates; a 

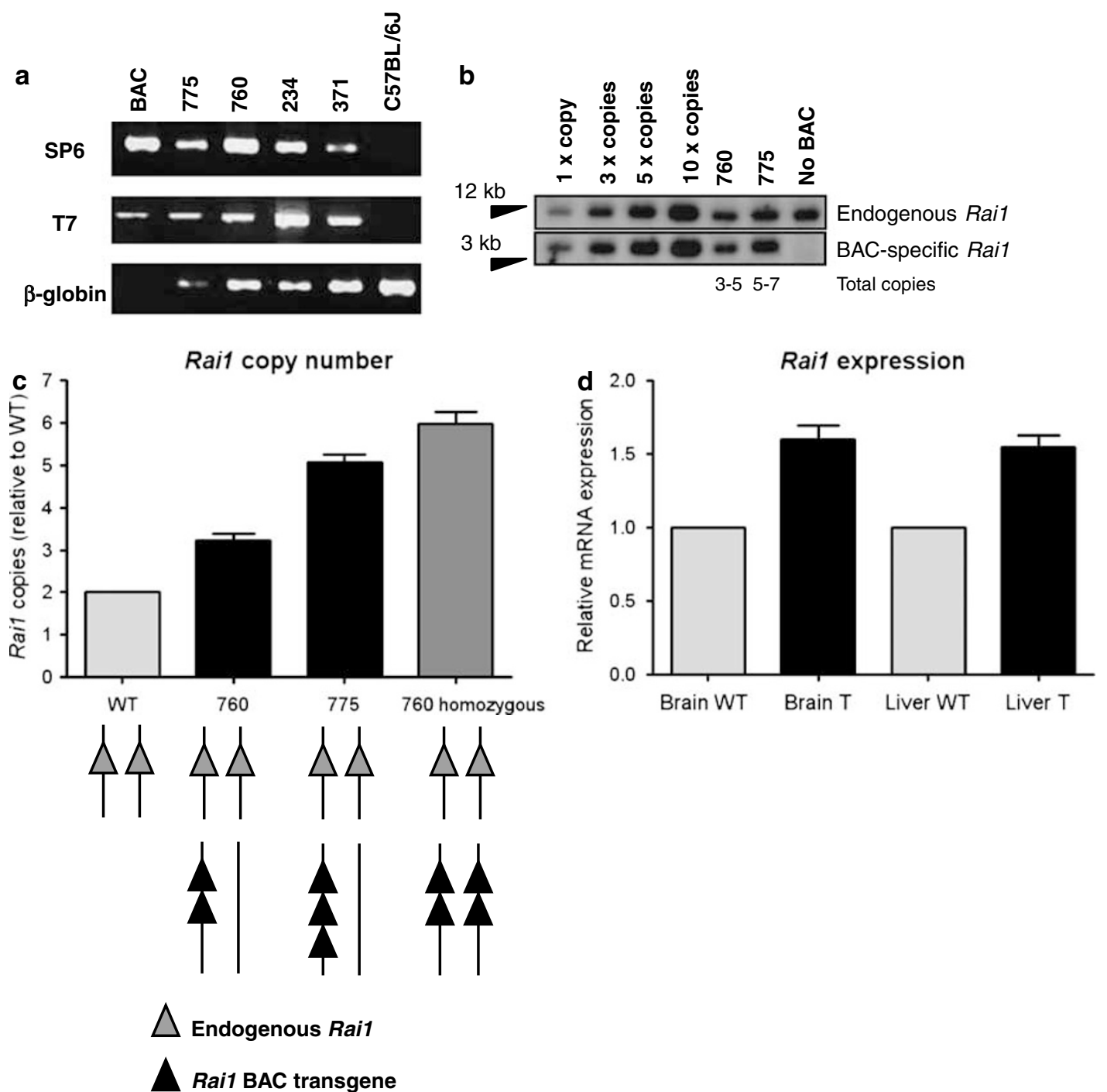

Figure 1 Genotyping of Rai1-transgenic mice. (a) Nonquantitative BAC specific PCR using mouse tail DNA and primers mapping to the unique SP6 and T7 ends of the BAC. $\beta$-globin was used as an internal control. Transgenic mice amplified both BAC-end PCRs and $\beta$-globin, whereas the wild-type C57BL/6 DNA amplified only $\beta$-globin. (b) Copy number analysis using Southern blotting probed with a full length Rai1 cDNA probe. Copy number standards denoting 1, 3, 5, and 10 copies of Rai1 in the BAC are shown. Results of copy number analysis from 760 and 775 male founder mice are also shown. The band intensities of the founder DNAs were compared to the copy standards for the total copy number determination (indicated below the founder DNA bands). (c) Real-time evaluation showing Rai1 copy number ( $y$ axis) relative to wild type, including copy number of founders, 760 $(n=12)$ and $775(n=4)$, and homozygous transgenic $(n=9)$ mice from the 760 line ( $x$ axis). A schematic illustrating the copy number in the wild type and Rai1 transgenics is shown (bottom). The exact insertion of the BAC transgene is not known. (d) Real-time expression analysis showing the relative levels of Rai1 cDNA in the wild type (WT) brain/liver, brain $(n=7)$, and liver $(n=6)$ samples isolated from the hemizygous transgenic $(\mathrm{T})$ mice (line 760) are shown. Each reaction was run in triplicate.

two-way ANOVA on total body length showed significant effect of age $(P<0.0001)$ and genotype $(P=0.0002)$ (Figure 2b). Thus, Rai1 transgenics have significant growth retardation early in life, but the body size normalizes by 20 weeks of age. At 30 weeks, the weights and lengths of transgenic mice were similar to those of non-transgenics. Similar growth retardation was also observed in the 775 transgenic line with significant reduction $(P<0.001)$ in body weight (Supplementary Figure S2). Craniofacial and limb measurements showed that the Rai1 transgenics have a proportionately smaller head and body sizes compared to their wild-type littermates (Supplementary data, Supplementary Figure S3A-G).

Open-field tests: Rai1-transgenic mice exhibit decreased rearing behavior, increased locomotor activity, and increased anxiety-related behaviors At the beginning of the F.O.B, open-field tests were conducted. Open-field tests evaluate the exploratory activity and anxiety-related responses when the mice are 
Table 1 Results of the modified SHIRPA protocol in Rai1transgenic mice

\begin{tabular}{|c|c|c|}
\hline & $\begin{array}{c}\text { Rai1 } \\
\text { transgenics }^{\mathrm{a}}\end{array}$ & $\begin{array}{l}\text { Non- } \\
\text { transgenics }\end{array}$ \\
\hline \multicolumn{3}{|c|}{ Physical assessment and simple reflexes (\% abnormal) } \\
\hline Whisker appearance & 8 & 6 \\
\hline Bald patches (\% with) & 4 & 2 \\
\hline Nails, teeth, or genitalia & 0 & 0 \\
\hline Righting reflex & 0 & 0 \\
\hline Sound orientation & 0 & 0 \\
\hline Whisker response & 8 & 6 \\
\hline Eye blink/ear twitch & 0 & 0 \\
\hline Pupil constriction/dilation & 0 & 0 \\
\hline \multicolumn{3}{|c|}{ General observational measurement (\% with) } \\
\hline Wild running ${ }^{b}$ & 21 & 2 \\
\hline Freezing & 0 & 2 \\
\hline Sniffing & 100 & 100 \\
\hline Licking & 100 & 100 \\
\hline Rearing & 75 & 78 \\
\hline Defecation & 100 & 100 \\
\hline Urination & 100 & 100 \\
\hline Stereotypies & 0 & 0 \\
\hline \multicolumn{3}{|c|}{ Sensorimotor reflexes and strength (\% abnormal) } \\
\hline Postural reflex & 0 & 0 \\
\hline $\begin{array}{l}\text { Response to being picked } \\
\text { up by tail }\end{array}$ & 0 & 0 \\
\hline $\begin{array}{l}\text { Hot-plate test (latency } \\
\text { (sec } \pm \text { SEM) to response) }\end{array}$ & $4.08 \pm 0.98$ & $6.05 \pm 1.5$ \\
\hline \multicolumn{3}{|l|}{ Gait test ${ }^{\mathrm{c}}$} \\
\hline Sway distance $(\mathrm{cm} \pm \mathrm{SEM})$ & $3.7 \pm 0.12$ & $2.7 \pm 0.15$ \\
\hline Stride distance $(\mathrm{cm} \pm$ SEM $)$ & $6.19 \pm 0.07$ & $7.53 \pm 0.14$ \\
\hline Stance distance $(\mathrm{cm} \pm \mathrm{SEM})$ & $2.7 \pm 0.05$ & $3.74 \pm 0.14$ \\
\hline Cage-top hang test ${ }^{c}(\sec \pm$ SEM $)$ & $5.25 \pm 1.92$ & $16.77 \pm 5.82$ \\
\hline \multicolumn{3}{|c|}{ Social interactions and home cage behaviors } \\
\hline $\begin{array}{l}\text { Nest building assessment } \\
\text { (\% abnormal) }\end{array}$ & 0 & 0 \\
\hline $\begin{array}{l}\text { Tube test for dominance } \\
\text { (number of wins) }\end{array}$ & $22^{d}$ & 11 \\
\hline
\end{tabular}

Table modified from Paylor et al. ${ }^{18}$

${ }^{a}$ All data presented are for Rai1 hemizygous transgenics; $n=24$ for transgenics, $n=51$ for non-transgenics unless otherwise explained in the text.

${ }^{\mathrm{b}} P<0.05$ by Fisher's exact test.

${ }^{\mathrm{c}} P<0.05$ by unpaired Student $t$ test.

${ }^{\mathrm{d}} P<0.05$ by one-sample $\chi^{2}$ test.

placed in an unfamiliar environment. ${ }^{11}$ Initially, rearing behavior or vertical activity of the mice were counted over a 5-min observation period. Rai1-transgenic mice displayed decreased rearing behavior compared to the non-transgenics at 10 weeks $(P<0.05)$ and 20 weeks of age, although both genotypes exhibited similar numbers of rears at 5 weeks of age (Figure 3a). Differences in rearing behavior have been associated with impaired anxiety-related responses, altered basal exploration, and abnormal motor coordination. ${ }^{11}$

A quantitative assessment of locomotor activity was performed in standard activity chambers interspersed with
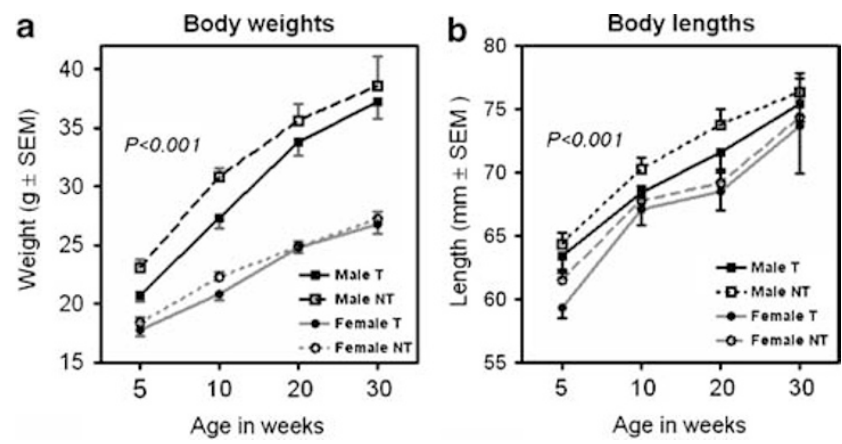

Figure 2 Growth assessment of transgenic and non-transgenic mice. Body weights (a) and body lengths (b), of male (bold black line) and female (bold gray line) hemizygous transgenic mice ( $T$ ) along with male (dotted black line) and female (dotted gray line) non-transgenic (NT) mice at different ages (in weeks) are shown ( $n \geq 15$ for each gender and genotype). Data were analyzed by a two-way ANOVA for genotype, age, and interaction.

photocell beams (see Materials and methods). Total locomotor counts were measured and the center to total counts ratio was calculated. The transgenic mice showed significantly increased motor activity compared to nontransgenic littermates at ages 5 and 10 weeks $(P<0.05)$ (Figure 3b). At 20 weeks, the motor activity counts of transgenic mice normalized to those of non-transgenic mice. Since the Rai1 transgenics were hyperactive, the center to total counts ratio was used to correct for any confounding effects due to increased locomotor activity to assess anxiety-related responses. ${ }^{11,19}$ Measurement of center/total locomotor counts indicates that transgenic mice spend a lesser proportion of their exploration in the center of the open field as compared to non-transgenics (Figure 3c). This finding demonstrates that transgenics avoid the center of the open field suggestive of higher anxiety levels.

\section{Rai1-transgenic mice have impaired neuromuscular strength and coordination and hypersensitivity to pain}

To test for neuromuscular coordination, mice were subjected to a series of tests for strength and sensorimotor reflexes. The cage-top hang test evaluates neuromuscular grip strength and motor coordination. Here, the mice are allowed to hold on to the cage-top, which is then inverted over the cage. The amount of time (s) the mouse remains hanging is noted. The transgenic mice (at 20 weeks) easily fall off the cage-top and thus display an impaired neuromuscular ability $(P<0.05)$ (Figure $3 \mathrm{~d}$, Table 1 ). Further supporting this, transgenic mice showed decreased ability to right themselves on an inverted screen compared to the non-transgenics (Table 2).

The hotplate test was performed to assess sensorimotor reflex response to a painful stimulus. Mice were placed on a hotplate $\left(55^{\circ} \mathrm{C}\right)$, and the latency to show their first hind 

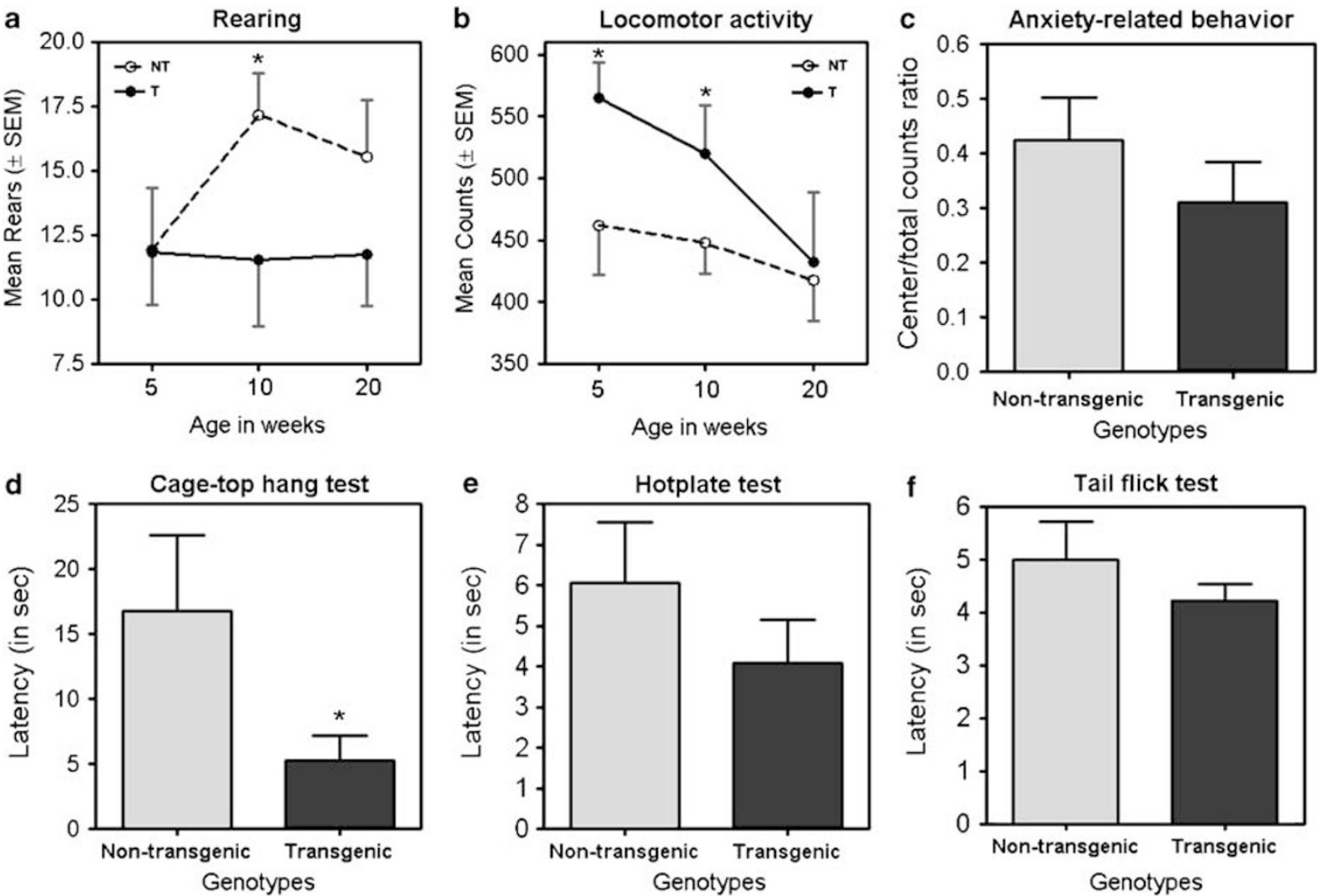

Figure 3 Assessment of rearing activity, locomotor activity, anxiety-related behavior, and neuromuscular and sensorimotor coordination. (a) Number of rears (vertical activity) exhibited by hemizygous transgenic (T) (bold line, $n=12$ ) and non-transgenic (NT) (dotted line, $n=11)$ mice over a 5 -min observation period at 5, 10, and 20 weeks are shown. The values for transgenic mice are significant at 10 weeks $(P<0.05)$. (b) Motor activity of transgenic (T) (bold line, $n=12$ ) and non-transgenic (NT) (dotted line, $n=12$ ) mice assessed by the total number of interruptions of photocell beams (mean counts) are shown. (c) Center/total distance ratio illustrating exploratory motor activity and anxiety-related behavior for non-transgenic ( $n \geq 6$ ) and transgenic mice $(n \geq 6)$ at age $\geq 20$ weeks is shown. (d) Latency (s) in a cage-top hang test for the transgenic $(n=10)$ and non-transgenic ( $n=8)$ mice performed at age 20 weeks are represented by histograms. P-values were calculated using unpaired $t$-tests. (e) Hotplate test to assess sensorimotor response to a painful stimulus (at age 20 weeks). The latency (s) to show the first hind limb response when placed on a hotplate is shown $(n \geq 15)$. (f). Tail flick test to assess the spinal reflex response to a temperature stimulus (at age 20 weeks). The mouse tail is exposed to a heat lamp and the latency (s) to flick its tail away from the heat is recorded $(n \geq 10) .{ }^{*} P<0.05$; results represent mean \pm SEM.

limb response was recorded. Although not statistically significant, transgenic mice were more sensitive to a painful stimulus with decreased latency to show their hind limb response compared to the non-transgenics (Table 1, Figure 3e). Similarly, transgenic mice demonstrated decreased latency on tail flick (Table 2, Figure 3f). Thus, transgenic mice showed consistent trends toward hyperresponsiveness to sensory stimuli, as apparent in both paradigms, compared to the non-transgenics.

\section{Rai1 transgenics exhibit gait abnormalities}

Gait tests were performed by foot-print analysis (see Materials and methods) at 20 weeks of age on both genotypes. The stride distance was significantly reduced in the transgenic mice $(P<0.0001)$, while the sway distance was increased, resulting in a shorter, wider gait in the transgenics compared to the non-transgenics $(P<0.0001)$ (Table 1, Figure 4). Furthermore, transgenic mice have a shorter stance compared to the non-transgenics $(P<0.0001)$. Abnormal gait could be due to reduced muscular tone, impaired cerebellar motor or peripheral neurological function, and/or due to an underlying musculoskeletal anomaly. ${ }^{20,21}$

\section{Social interactions and home-cage behaviors}

To evaluate social interactions, we used a tube test, a paradigm used to evaluate social dominance. ${ }^{22}$ Mice were evaluated at 10 and 20 weeks of age and a total of 48 trials were conducted with 24 transgenics and 24 non-transgenics. Each transgenic mouse was tested twice with a different non-transgenic mouse (one from the same cage and another from a different cage) of the same gender. Transgenic animals won 22 times and non-transgenic mice won 11 times $\left(\chi^{2}\right.$ (one sample) test, ${ }^{22} \chi^{2}=7.2 ; P<0.05$ ) while 15 trials did not yield any win (Table 1). No differences were observed between mice from the same or 
Table 2 Summary of the functional observational battery in Rai1 transgenic mice

\begin{tabular}{|c|c|c|c|}
\hline & $\begin{array}{c}\text { Non-transgenic mice } \\
(n=12)\end{array}$ & $\begin{array}{l}\text { Rai1 hemizygous } \\
\text { transgenic mice }(n=13)\end{array}$ & $\begin{array}{l}\text { Rai1 homozygous } \\
\text { transgenic mice }(n=9)\end{array}$ \\
\hline \multicolumn{4}{|l|}{ CNS activity } \\
\hline Posture & Normal & Normal & Normal \\
\hline CNS excitability & Normal & Abnormal & Exaggerated \\
\hline Tonic movements & Absent & Absent & Absent \\
\hline Clonic movements & Absent & Absent & Absent \\
\hline \multicolumn{4}{|l|}{ Autonomic effects } \\
\hline Palpebral closure & Normal & Normal & Normal \\
\hline Urination & Normal & Normal & Normal \\
\hline Defecation & Normal & Normal & Normal \\
\hline \multicolumn{4}{|l|}{ Psychomotor coordination } \\
\hline Rearing response/vertical activity & Normal & Decreased & Decreased \\
\hline Muscle tone/equilibrium & Normal & Abnormal & Abnormal \\
\hline Mobility/locomotor activity & Normal & Abnormal & Exaggerated \\
\hline Inverted screen & Normal & Abnormal & Abnormal \\
\hline Forelimb grip strength & Normal & Decreased & Decreased \\
\hline Landing splay & Normal & Normal & Abnormal \\
\hline \multicolumn{4}{|l|}{ Sensorimotor reactivity (\% with) } \\
\hline \multicolumn{4}{|l|}{ Response to arousal } \\
\hline Very low (stupor/coma) & 0 & 0 & 0 \\
\hline Low & 0 & 0 & 0 \\
\hline Sluggish & 24 & 0 & 0 \\
\hline Normal & 71 & 12 & 4 \\
\hline High & 6 & 76 & $92 *$ \\
\hline Exaggerated & 0 & 12 & 4 \\
\hline \multicolumn{4}{|l|}{ Response to approach } \\
\hline No reaction & 6 & 3 & 0 \\
\hline Sniffs & 72 & $91^{*}$ & 65 \\
\hline Freezes & 9 & 3 & 23 \\
\hline Energetic response & 9 & 0 & 12 \\
\hline Exaggerated response & 3 & 3 & 0 \\
\hline \multicolumn{4}{|l|}{ Response to click } \\
\hline No reaction & 5 & 0 & 0 \\
\hline Slight reaction & 24 & 38 & 44 \\
\hline Freezes & 48 & 25 & 36 \\
\hline Energetic response & 19 & 32 & 12 \\
\hline Exaggerated response & 4 & 3 & 8 \\
\hline \multicolumn{4}{|l|}{ Response to touch } \\
\hline No reaction & 0 & 0 & 0 \\
\hline Slowly turns & 36 & 32 & 29 \\
\hline Freezes & 39 & 45 & 50 \\
\hline Energetic response & 21 & 18 & 12 \\
\hline Exaggerated response & 3 & 2 & 9 \\
\hline \multicolumn{4}{|l|}{ Response to tail pinch } \\
\hline No reaction & 4 & 0 & 0 \\
\hline Turns away & 32 & 32 & 39 \\
\hline Freezes & 24 & 48 & 35 \\
\hline Energetic response & 32 & 16 & 17 \\
\hline Exaggerated response & 8 & 4 & 9 \\
\hline Tail flick test & $4.98 \pm 0.72$ & $4.09 \pm 0.32$ & $N A^{a}$ \\
\hline
\end{tabular}

${ }^{a}$ Tail flick test was not possible due to hyperactive behavior in homozygous mice.

${ }^{*} P<0.05$, compared to non-transgenic mice.

a different cage, and no gender or age-specific differences were observed. Although a confounding effect of hyperactivity cannot be excluded in the transgenics, our analysis suggests that transgenics are socially dominant compared to their wild-type littermates. Assessment of the nest building ability and homing behavior in both transgenic 

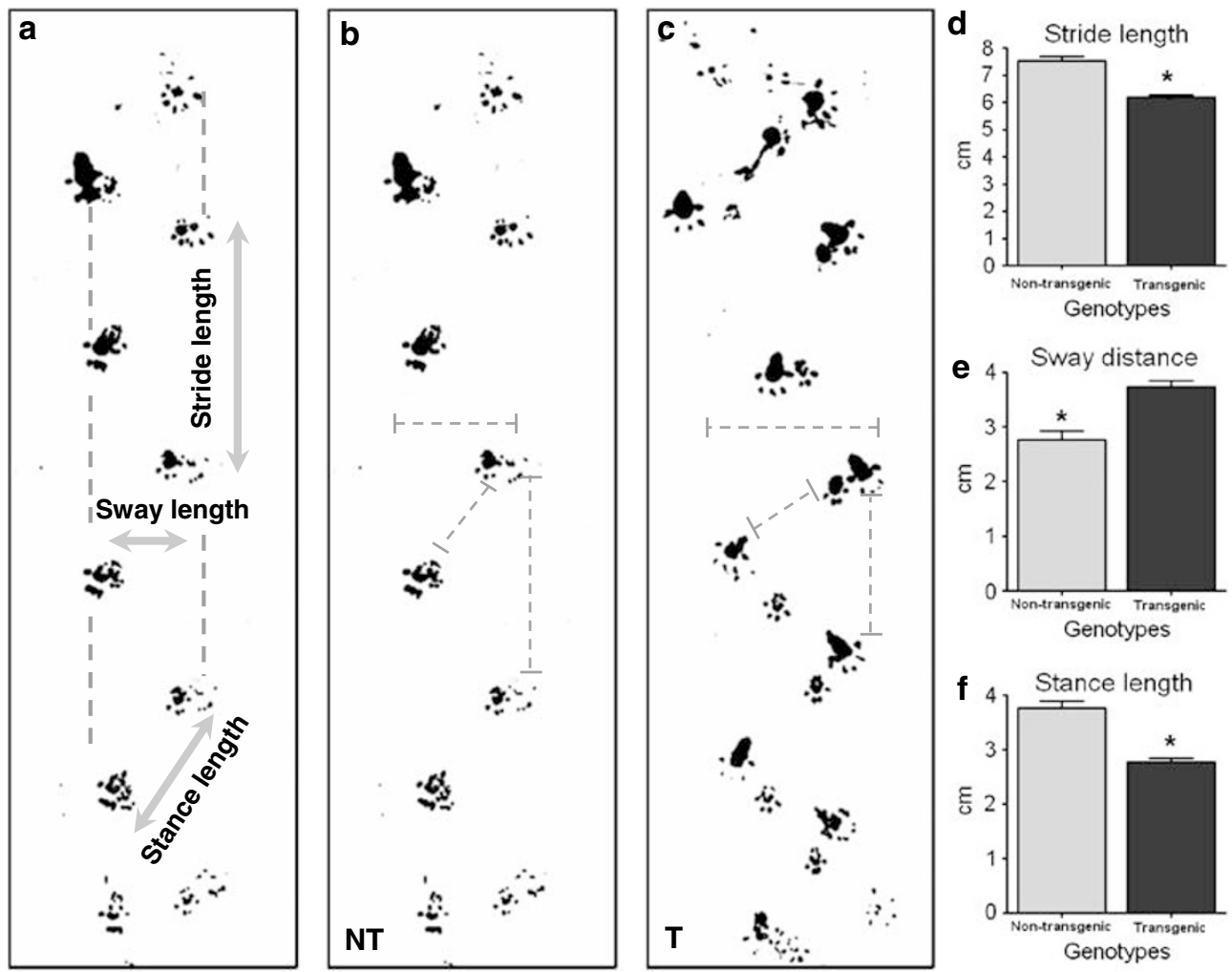

Figure 4 Gait test. (a) Parameters measured in footprint analysis with dotted lines representing the direction of progression (DoP) of walking are shown. (b) Footprints of transgenic $(n \geq 10)$ and (c) non-transgenic mice $(n \geq 10)$ at 20 weeks were evaluated for stride length, sway length, and stance $(\mathrm{cm})$. Histograms represent differences in: (d) stride length, (e) sway length, and (f) stance in transgenic (T) and non-transgenic (NT) mice $\left({ }^{*} P<0.05\right)$.

and normal littermates did not reveal any significant differences (Table 1).

\section{Circadian rhythm analysis}

Wheel running activity was monitored for $24 \mathrm{~h}$ for 3 weeks in constant darkness (DD) after entrainment in a light:dark (12L:12D) cycle. Although circadian periods in transgenics were shortened by $6 \mathrm{~min}$, overall there was no statistically significant difference in the average circadian period between the two genotypes (Supplementary Figure S4).

\section{Gross organ evaluations and histological and serum analysis}

To identify any morphological or systemic organ anomalies due to Rai1 overexpression, postmortem dissections and histological analyses of transgenic and non-transgenic mice were performed. The gross anatomy of brain, liver, kidneys, spleen, heart, and thymus was unchanged in transgenic mice compared with their normal littermates (Supplementary Figure S5). H and E staining of sectioned tissues did not reveal any visible difference in any of the organs examined with the exception of the transgenic liver sections, which showed a larger nucleus resulting in an increased nuclear:cytoplasmic ratio compared to the non-transgenic livers (Supplementary Figure S5). Transgenic and non-transgenic mice were analyzed to identify any liver and metabolic abnormalities associated with Srebp1 overexpression, a gene also contained in the BAC. Analysis of serum showed no difference in the levels of liver enzymes (Supplementary Figure S6A). Although there was an increase in the levels of cholesterol, triglycerides, and glucose in transgenic animals consistent with Srebp1 overexpression, ${ }^{23}$ the difference was not statistically significant (Supplementary Figure S6B). Since only 3 end of Tom1l2 is contained in the BAC, any potential effect of this gene was ruled out.

\section{Rai1-transgenic mice exhibit dosage-dependent exacerbation of the phenotype}

To determine if there is an enhanced effect of the hitherto described Rai1 transgenic phenotype, we mated Rai1 hemizygous transgenic males and females to create Rai1 homozygous transgenic mice with six copies of Rai1 and $>2$-fold mRNA expression (Figure 1c). The homozygous transgenic pups were obtained mainly by cross-fostering to non-transgenic mothers owing to the fact that the female transgenic hemizygotes had smaller litter sizes and few surviving pups. These mice were further evaluated for the 
a

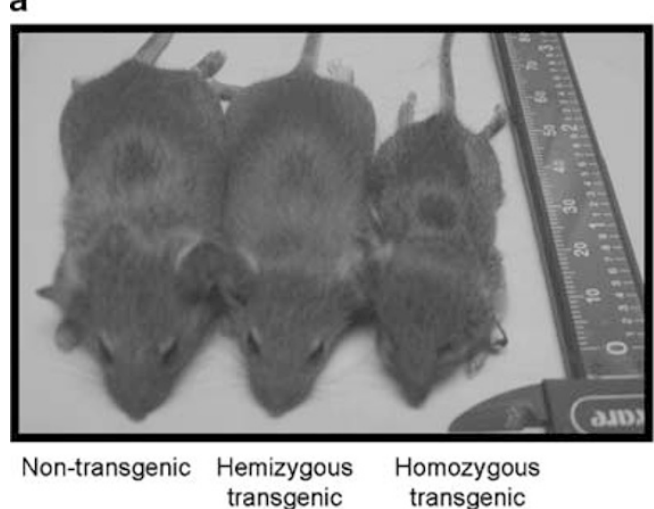

C

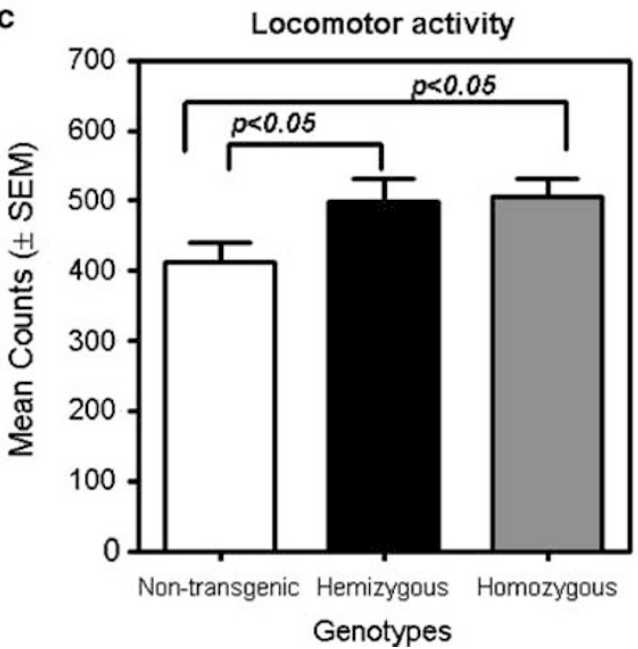

b

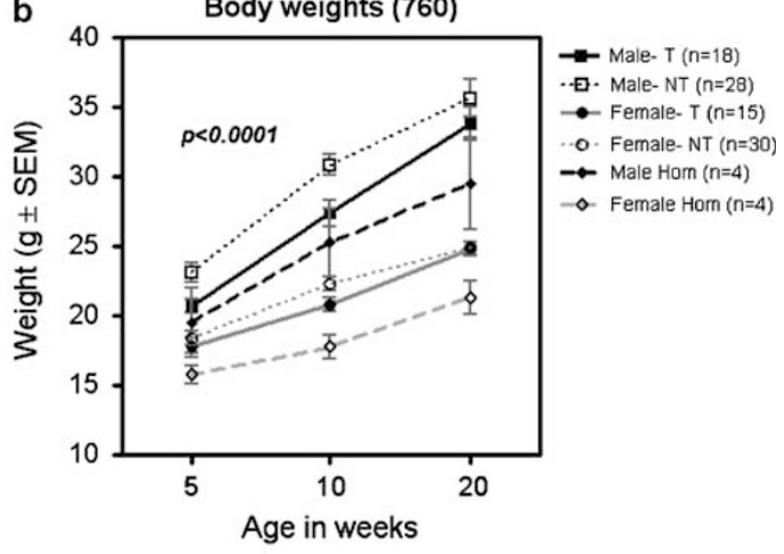

d

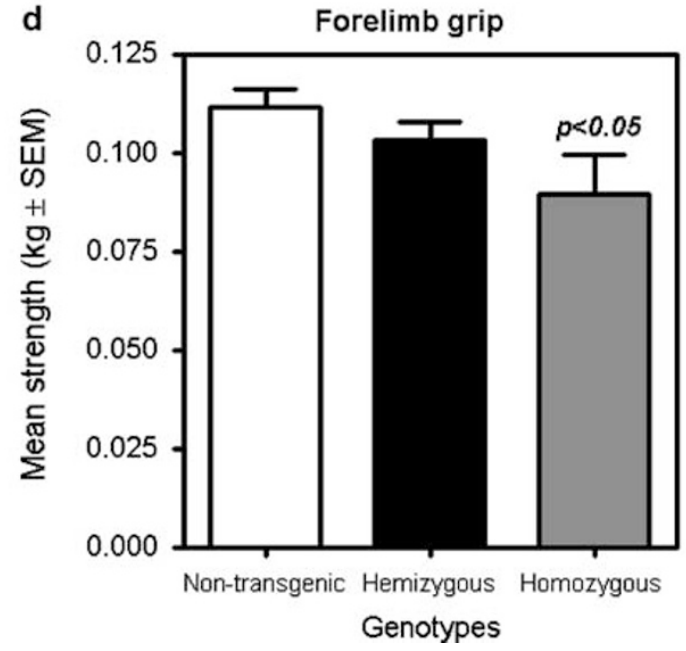

Figure 5 Dosage-dependent exacerbation of severity of the phenotype in Rai1-transgenic mice. (a) Relative sizes of Rai1 non-transgenic, hemizygous transgenic, and homozygous transgenic mice at 10 weeks are shown. (b) Growth curves of Rai1 overexpressing homozygous transgenic mice compared to Rai1 hemizygous transgenic and non-transgenic mice. Mice were weighed at ages 5, 10, and 20 weeks. Statistical analysis was performed using ANOVA for the effect of genotype, age, and interaction. The numbers of mice (n) of each genotype used for evaluation are shown. (c) Motor activity (number of interruptions of photocell beams). (d) Forelimb grip strength (kg). For (c) and (d), $n=12$ (non-transgenic), $n=11$ (hemizygous transgenic), and $n=9$ (homozygous transgenic).

developmental, neurological, and behavioral paradigms described below (Table 2). Visually, the Rai1 homozygous transgenic animals were slender, small-for-age, but very active and difficult to handle (Supplementary video; Table 2; Figure 5a). Body weight and measurements were taken at 5, 10, and 20 weeks. A two-way ANOVA with the body weights indicates a significant growth retardation in the homozygous transgenic mice compared to the hemizygous transgenic and non-transgenic mice with significant effect of genotype $(P<0.0001)$ and age $(P<0.0001)$ (Figure 5a and $\mathrm{b}$ ).

Preliminary evaluations of homozygous transgenic mice documented a significant hyperactive, possibly stressinduced behavior, which precluded testing for several behavioral paradigms, including inverted screen test, cage-top hang test, and social behaviors (Table 2). To illustrate this hyperactive behavior, the degree of difficulty in handling homozygous transgenic mice and the ease of removal of these mice from a cage were graded in an ordinal scale (Supplementary Figure S5A, B and Supplementary video). The observer experienced greater difficulty in handling the homozygous transgenics and in removal of these mice from the cage compared to the other genotypes (Supplementary Figure S7). The majority of homozygous transgenics resorted to biting or squirming when handled (Table 2; Supplementary Figure S7). Evaluation of locomotor activity in the Rai1 homozygous transgenic mice showed that the mean counts were significantly different from those of non-transgenics $(P<0.05)$ but were similar to those of hemizygous transgenic mice (Figure $5 b$ ). Forelimb grip strength was measured by using a strain gauge, and the force pulled $(\mathrm{kg})$ was recorded. Results from forelimb grip strength test indicated a decreasing trend in neuromuscular function with homozygous transgenic mice showing 
significantly low grip strengths $(P<0.05)$ compared to the other genotypes (Figure 5c). Furthermore, reduced rearing behavior among the homozygous transgenics was observed, although this was not significantly different from the hemizygous transgenics (data not shown).

Thus, in these paradigms, the transgenic mice showed a dosage-dependent exacerbation of the phenotype (in order of increasing severity: non-transgenics $<$ hemizygous transgenics $<$ homozygous transgenics), a trend consistent with increased Rai1 copy number.

\section{Discussion}

The use of transgenic mice has been beneficial to study the effect of overexpression or copy number variation of a single gene $\mathrm{e}^{24,25}$ or a group of genes involved in segmental aneuploidy. ${ }^{26,27}$ While haploinsufficiency of RAI1 results in the majority of clinical features of SMS, its role in the reciprocal duplication $17 \mathrm{p} 11.2$ syndrome is not clearly understood. ${ }^{4,5}$ Human chromosome 17 is syntenic to a approximately 34-cM region of mouse chromosome 11 , in which 19 genes are conserved in order and orientation. ${ }^{28,29}$ Mouse models for SMS and $\operatorname{dup}(17)(\mathrm{p} 11.2 \mathrm{p} 11.2)$ syndromes, $D f(11) 17+$ and $D p(11) 17+$, heterozygous for either a deletion or a duplication, respectively, encompassing an approximately $3 \mathrm{Mb}$ mouse syntenic region, have been created, while a gene targeting approach was used to create Rai1 ${ }^{+/-}$mice (Table 3). ${ }^{30,31}$ Studies showed that both the deletion ${ }^{31,34}$ and the Rai1 ${ }^{+/-}$mice $^{30}$ manifested with craniofacial abnormalities, obesity, altered circadian rhythm, seizures, and hypoactivity, with the few viable Rai $^{-/-}$mice exhibiting severe neurological abnormalities, motor dysfunction, overt seizures, and learning deficits (Table 3). ${ }^{33}$ Evaluation of the duplication mice showed hyperactivity, reduced weight, and impaired fear conditioning. ${ }^{31}$ Although rescue of the phenotypes in both the deletion and the duplication mice was shown in the compound heterozygous ( $\mathrm{dup} / \mathrm{del}$ ) mice, not all phenotypic features were rescued in the duplication/Rai1 ${ }^{+/}$mice (Table 3). ${ }^{29}$ Furthermore, these mice were created and evaluated in a mixed genetic background (C57BL/6 $\mathrm{Tyr}^{\mathrm{c}-\mathrm{Brd}} \times 129 \mathrm{~S} 5 / \mathrm{SvEBrd}$ ), resulting in incomplete penetrance for many of the traits observed, complicating the phenotypic analysis (Table 3). ${ }^{29,30}$ To analyze the gene-dosage effect of Rai1, we created BAC-transgenic mice overexpressing the Rai1 gene in the C57BL/6J background (Figures 1 and 6). Although the transgene expression pattern has not been tested in our mice, transgenesis was confirmed by expression and phenotypic analyses of two transgenic lines with

Table 3 Phenotypes in mouse models with varying copy numbers of Rai1

\begin{tabular}{|c|c|c|c|c|c|c|c|}
\hline Phenotypic features & $\begin{array}{c}\text { Rai1 } \\
\text { homozygous } \\
\text { transgenic } \\
\text { (6 copies) }^{a}\end{array}$ & $\begin{array}{c}\text { Rai1 } \\
\text { hemizygous } \\
\text { transgenic } \\
\text { (4 copies) }^{\mathrm{a}}\end{array}$ & $\begin{array}{c}\text { Dp }(11) 17 /+ \\
\text { (3 copies Rai1 }^{b} \\
\text { and other genes) }\end{array}$ & $\begin{array}{l}\text { Dp }(11) 17 / \text { Rai1 }- \\
(2 \text { copies Rai1) }\end{array}$ & $\begin{array}{l}\text { Rai1 }+/- \\
(1 \text { copy })^{\mathrm{d}}\end{array}$ & $\begin{array}{l}D f(11) 17 /- \\
\quad(1 \text { copy })^{\mathrm{b}}\end{array}$ & $\begin{array}{l}\text { Rai1-/- } \\
(\text { knockout })^{\mathrm{d}}\end{array}$ \\
\hline Background & C57Bl6/J & C57Bl6/J & Mixed & Mixed & Mixed & Mixed & Mixed \\
\hline Growth retardation & ++ & + & - & - & - & - & + \\
\hline Reduced weight & ++ & + & + & - & - & - & - \\
\hline Craniofacial anomalies & - & - & - & NA & $+(18 \%)$ & $+(70-80 \%)$ & $+(100 \%)$ \\
\hline Hyperactivity & ++ & + & + & - & - & - & - \\
\hline Hypoactivity & - & - & - & - & + & + & - \\
\hline $\begin{array}{l}\text { Abnormal circadian } \\
\text { rhythm }\end{array}$ & - & - & - & NA & + & + & NA \\
\hline $\begin{array}{l}\text { Abnormal anxiety-related } \\
\text { responses }\end{array}$ & + & + & - & - & + & - & NA \\
\hline Sensorimotor impairment & ++ & + & + & - & - & - & - \\
\hline Motor dysfunction & ++ & + & - & - & + & + & ++ \\
\hline Gait abnormalities & $N A^{e}$ & + & NA & NA & NA & NA & NA \\
\hline Seizures & - & - & - & - & + & + & + \\
\hline Impaired conditioned fear & NA & NA & + & - & - & - & + \\
\hline \multicolumn{8}{|l|}{ Reduced fecundity } \\
\hline Males & + & - & - & NA & - & - & + \\
\hline Females & + & + & - & NA & NA & - & + \\
\hline
\end{tabular}

Shaded columns represent mice described in the current study. The non-shaded columns represent deletion or duplication of mouse syntenic regions containing Rai1 or gene-targeted knockout of Rai1.

++ Indicates exaggerated severity, + present, - absent, and NA not assessed for that particular feature. Numbers in parenthesis indicates penetrance. apresent study.

balz et al, 2004. ${ }^{32}$

'Walz et al, 2006. ${ }^{29}$

${ }^{\mathrm{d}} \mathrm{Bi}$ et al, 2005, 2007.30,33

${ }^{\mathrm{e}}$ Gait tests were not possible in homozygous mice because of extreme difficulty in handling. 


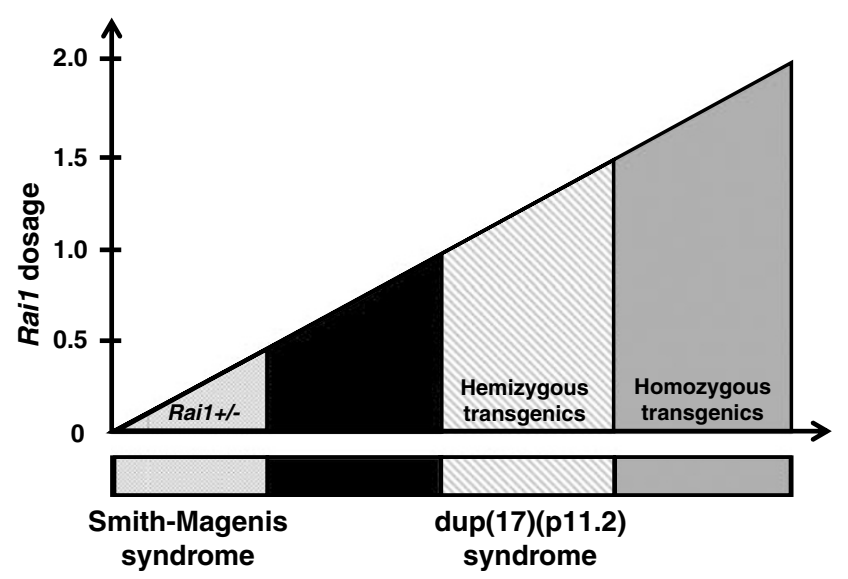

Figure 6 Rai1 dosage-thresholds and phenotypes due to altered Rai1 dosage. A graph representing Rai1 mouse models (Rai1 heterozygous knockout, Rai1 hemizygous BAC-transgenic, and Rai1 homozygous BAC-transgenic mice) on the $x$ axis and increasing mean Rai1 expression levels or dosage on the $y$ axis is shown. RAl1 dosage thresholds and associated human syndromes (Smith-Magenis and dup(17)(p11.2) syndromes) due to altered RAl1 levels are also shown below the $x$ axis. The black shaded region represents RAl1/Rai1 levels at which no discernable phenotype is observed.

correspondence between expression levels and Rai1 copy number in both lines, controlling for any putative positional effect due to the integration site. ${ }^{24}$ We did not anticipate any potential dosage effects of Srebp1 and Tom1l2 genes, which are also contained in the BAC, as no behavioral phenotypes have been associated with Srebp 1 or Tom112 mice (Shimano, 2000; Girirajan et al, unpublished data). ${ }^{23}$

Rai1 hemizygous transgenic mice exhibit growth retardation prior to 20 weeks of age, while the homozygous transgenics remain small even after 30 weeks of age. Patients with SMS as well as individuals with dup(17)(p11.2) syndrome have a definitive delay in growth during early childhood. ${ }^{1,4}$ The growth deficiency observed in the transgenic animals is possibly due to an involvement of Rai1 in body energy and metabolic regulation; however, feeding behavior, neural regulation, and pituitary control of somatic growth cannot be ruled out. ${ }^{35}$ Since Rai1 ${ }^{+/-}$ mice are obese and those overexpressing Rai1 are lean and growth retarded, mirroring the phenotypes observed in the corresponding human syndromes, there appears to be a direct correlation between Rai1 dosage and body mass, pointing to a conserved regulatory pathway between mouse and human. Further study is required to dissect its specific role.

Craniofacial measurements of Rai1 transgenics showed significant sexual dimorphism, but no obvious difference between transgenics and non-transgenics was observed. This correlates with $\operatorname{dup}(17)(\mathrm{p} 11.2)$ patients who have subtle, sometimes difficult to discern, craniofacial features such as triangular face, microcephaly, hypertelorism, and broad nasal bridge, ${ }^{1,5}$ furthermore, the duplication mouse model, $D p(11) 17 /+$, did not show any craniofacial anomalies. ${ }^{31}$ Thus, increased copy number/overexpression of Rai1 has little to no effect on craniofacial development. Similarly, no major organ defect, evaluated by gross morphological or histological analysis on transgenic tissues, or circadian rhythm anomalies were observed in our transgenic mice, thus, corroborating the $D p(11) 17 /+$ data. $^{32}$

Spontaneous locomotor activity in the hemizygous transgenic mice is inversely correlated to body size with motor activity counts decreasing with age, normalizing at 20 weeks of age. Furthermore, the homozygous transgenic mice were hyperactive and so difficult to handle that evaluation for several behavioral paradigms was not possible. Correspondingly, $\operatorname{dup}(17)(\mathrm{p} 11.2)$ patients are hyperactive and are often diagnosed with attention-deficit hyperactivity disorder (ADHD). ${ }^{5} \mathrm{~A}$ major consequence of extreme behaviors in homozygous transgenic mice was reduced fecundity in both males and females (Table 3). The transgenic mice spend less time hanging in the cage-top hang test and have reduced forelimb grip strength, while analysis of the responses to stimulus reactivity tests showed that the transgenic mice, in increasing order of Rai1 dosage, have altered sensorimotor coordination. To evaluate motor function and gaiting, gait tests were performed at 20 weeks to remove any confounding effects of body weight and size on gait pattern. The transgenic mice have an altered gait, with short strides, small stance, and abnormally wide sways, implicating Rai1 in cerebellar motor or neuromuscular function. Moreover, the Rai1 hemizygous and homozygous transgenics displayed exaggerated responses to handling, removal from cage, and arousal. Transgenics showed hypersensitivity to a painful stimulus and demonstrated reduced latency to tail-flick and hotplate tests compared to the non-transgenics. These data in mice are more consistent with altered RAI1 dosage directly influencing sensitivity and tolerance to pain as seen in patients with SMS and dup(17)(p11.2) syndrome.

A review of the mouse models involving Rai1, including our present study, indicates that any alteration from the normal, disomic copy number of Rai1 results in impaired growth and development and neurological and behavioral phenotypes (Table 3). Rai1 seems to have a global task in regulation of growth and development; however, its function in the predominantly expressed regions of the brain (including striatum, hippocampus, cerebellum, and the cerebral cortex) for modulating neurobehavioral endophenotypes is not clearly understood. ${ }^{33}$ While downregulation of dopamine receptor genes in the striatum results in hyperactivity and spontaneous behavior in mice, decreased exploratory rearing activity has been associated with altered hippocampal oscillatory activity. ${ }^{36,37}$ Thus, Rai1 might play an important role in the hippocampus and striatal dopaminergic systems in modulating adaptive 
processes associated with exploratory and emotional behavior. ${ }^{38}$ Gait abnormalities due to cerebellar dysfunction $^{39}$ or neurodegeneration have been reported in mouse models for lysosomal storage diseases, ${ }^{40,41}$ genes within the Down syndrome critical region, ${ }^{42}$ genes encoding presynaptic proteins, ${ }^{43}$ deficiency of transcription factors, ${ }^{20,21}$ musculoskeletal disorders, ${ }^{44}$ and polyglutamine diseases. ${ }^{45}$ Although the number of polymorphic polyglutamine repeats in human $R A I 1$ is implicated in modulating the onset of spinocerebellar ataxia, ${ }^{46}$ mice carry only four glutamines in this region, and polymorphic CAG repeats have not been reported.

Our studies show that Rai1 modulates neurological and developmental processes in a dosage-dependent manner and plays a vital role in growth, development, and behavior. A recent report from $T b x 1$ mice also shows that there are many developmental process-specific thresholds for $T b \times 1$ dosage beyond which the phenotype worsens. ${ }^{47}$ Similarly, it is likely that Rai1 functions within a dosagewindow (black shaded region in Figure 6), deviation from which leads to phenotypic manifestations associated with SMS and $\operatorname{dup}(17)(\mathrm{p} 11.2)$ syndrome (Figure 6). While homology studies have predicted a transcriptional role for Rai1, ${ }^{7,9}$ further investigations are necessary to understand the molecular targets and pathways in which Rai1 functions.

\section{Acknowledgements}

We acknowledge Dr Mario Dance at Virginia Commonwealth University for helping with collection of blood samples and care of mice, Dr Thom Saunders and Elizabeth Hughes from the University of Michigan Transgenic Animal Core, Catherine Barth and Tiffany Newton for preliminary mouse evaluations, and Dr Michael Grotewiel, Dr Christopher Vlangos, Stephen Williams, and Lily Hoa Truong for critical reading of the manuscript. We thank the histopathology core at the Michigan State University and the Comparative Pathology Lab at UC Davis for mouse tissue and serum studies. This work was supported, in part, by NIH RO1 HD38534 and by resources from Michigan State University and Virginia Commonwealth University.

\section{Conflict of interest}

The authors declare no conflict of interest.

\section{References}

1 Girirajan S, Williams SR, Garbern JY, Nowak N, Hatchwell E, Elsea SH: $17 \mathrm{p} 11.2 \mathrm{p} 12$ triplication and del(17)q11.2q12 in a severely affected child with dup(17)p11.2p12 syndrome. Clin Genet 2007; 72: $47-58$

2 Slager RE, Newton TL, Vlangos CN, Finucane B, Elsea SH: Mutations in RAI1 associated with Smith-Magenis syndrome. Nat Genet 2003; 33: 466-468.

3 Smith AC, McGavran L, Robinson J et al: Interstitial deletion of (17)(p11.2p11.2) in nine patients. Am J Med Genet 1986; 24: 393-414.

4 Girirajan S, Vlangos CN, Szomju BB et al: Genotype-phenotype correlation in Smith-Magenis syndrome: evidence that multiple genes in $17 \mathrm{p} 11.2$ contribute to the clinical spectrum. Genet Med 2006; 8: 417-427.

5 Potocki L, Bi W, Treadwell-Deering D et al: Characterization of Potocki-Lupski syndrome (dup(17)(p11.2p11.2)) and delineation of a dosage-sensitive critical interval that can convey an autism phenotype. Am J Hum Genet 2007; 80: 633-649.

6 Toulouse A, Rochefort D, Roussel J, Joober R, Rouleau GA Molecular cloning and characterization of human RAI1, a gene associated with schizophrenia. Genomics 2003; 82: 162-171.

7 Gerber HP, Seipel K, Georgiev O et al: Transcriptional activation modulated by homopolymeric glutamine and proline stretches. Science 1994; 263: 808-811.

8 Aasland R, Gibson TJ, Stewart AF: The PHD finger: implications for chromatin-mediated transcriptional regulation. Trends Biochem Sci 1995; 20: 56-59.

9 Girirajan S, Elsas II LJ, Devriendt K, Elsea SH: RAI1 variations in Smith-Magenis syndrome patients without $17 \mathrm{p} 11.2$ deletions. J Med Genet 2005; 42: 820-828.

10 Imai Y, Suzuki Y, Matsui T, Tohyama M, Wanaka A, Takagi T: Cloning of a retinoic acid-induced gene, GT1, in the embryonal carcinoma cell line P19: neuron-specific expression in the mouse brain. Brain Res Mol Brain Res 1995; 31: 1-9.

11 Crawley JN, Paylor R: A proposed test battery and constellations of specific behavioral paradigms to investigate the behavioral phenotypes of transgenic and knockout mice. Horm Behav 1997; 31: $197-211$

12 Irwin S: Comprehensive observational assessment: Ia. A systematic, quantitative procedure for assessing the behavioral and physiologic state of the mouse. Psychopharmacologia 1968; 13: 222-257.

13 Rogers DC, Fisher EM, Brown SD, Peters J, Hunter AJ, Martin JE: Behavioral and functional analysis of mouse phenotype: SHIRPA, a proposed protocol for comprehensive phenotype assessment. Mamm Genome 1997; 8: 711-713.

14 Moser VC, McCormick JP, Creason JP, MacPhail RC: Comparison of chlordimeform and carbaryl using a functional observational battery. Fundam Appl Toxicol 1988; 11: 189-206.

15 Tegeris JS, Balster RL: A comparison of the acute behavioral effects of alkylbenzenes using a functional observational battery in mice. Fundam Appl Toxicol 1994; 22: 240-250.

16 Ballester M, Castello A, Ibanez E, Sanchez A, Folch JM: Real-time quantitative PCR-based system for determining transgene copy number in transgenic animals. Biotechniques 2004; 37: 610-613.

17 Mogass M, York TP, Li L, Rujirabanjerd S, Shiang R: Genomewide analysis of gene expression associated with Tcof1 in mouse neuroblastoma. Biochem Biophys Res Commun 2004; 325: 124-132.

18 Paylor R, Nguyen M, Crawley JN, Patrick J, Beaudet A, OrrUrtreger A: Alpha7 nicotinic receptor subunits are not necessary for hippocampal-dependent learning or sensorimotor gating: a behavioral characterization of Acra7-deficient mice. Learn Mem 1998; 5: 302-316.

19 Peier AM, McIlwain KL, Kenneson A, Warren ST, Paylor R, Nelson DL: (Over)correction of FMR1 deficiency with YAC transgenics: behavioral and physical features. Hum Mol Genet 2000; 9: $1145-1159$

20 Reimold AM, Grusby MJ, Kosaras B et al: Chondrodysplasia and neurological abnormalities in ATF-2-deficient mice. Nature 1996; 379: $262-265$.

21 Tourtellotte WG, Milbrandt J: Sensory ataxia and muscle spindle agenesis in mice lacking the transcription factor Egr3. Nat Genet 1998; 20: 87-91.

22 Lijam N, Paylor R, McDonald MP et al: Social interaction and sensorimotor gating abnormalities in mice lacking Dvl1. Cell 1997; 90: 895-905

23 Shimano H: Sterol regulatory element-binding proteins (SREBPs): transcriptional regulators of lipid synthetic genes. Prog Lipid Res 2001; 40: 439-452.

24 Chrast R, Scott HS, Madani R et al: Mice trisomic for a bacterial artificial chromosome with the single-minded 2 gene (Sim2) show phenotypes similar to some of those present in the partial 
trisomy 16 mouse models of Down syndrome. Hum Mol Genet 2000; 9: 1853-1864.

25 Yang XW, Wynder C, Doughty ML, Heintz N: BAC-mediated gene-dosage analysis reveals a role for Zipro1 (Ru49/Zfp38) in progenitor cell proliferation in cerebellum and skin. Nat Genet 1999; 22: 327-335.

26 Funke B, Epstein JA, Kochilas LK et al: Mice overexpressing genes from the 22q11 region deleted in velo-cardio-facial syndrome/ DiGeorge syndrome have middle and inner ear defects. Hum Mol Genet 2001; 10: 2549-2556.

27 Roper RJ, Reeves RH: Understanding the basis for Down syndrome phenotypes. PLoS Genet 2006; 2: e50.

$28 \mathrm{Bi} \mathrm{W}$, Yan J, Stankiewicz P et al: Genes in a refined SmithMagenis syndrome critical deletion interval on chromosome $17 \mathrm{p} 11.2$ and the syntenic region of the mouse. Genome Res 2002; 12: $713-728$.

29 Walz K, Paylor R, Yan J, Bi W, Lupski JR: Rai1 duplication causes physical and behavioral phenotypes in a mouse model of dup(17)(p11.2p11.2). J Clin Invest 2006; 116: 3035-3041.

30 Bi W, Ohyama T, Nakamura $\mathrm{H}$ et al: Inactivation of Rai1 in mice recapitulates phenotypes observed in chromosome engineered mouse models for Smith-Magenis syndrome. Hum Mol Genet 2005; 14: 983-995.

31 Walz K, Caratini-Rivera $\mathrm{S}$, Bi $\mathrm{W}$ et al: Modeling $\operatorname{del}(17)(\mathrm{p} 11.2 \mathrm{p} 11.2)$ and $\operatorname{dup}(17)(\mathrm{p} 11.2 \mathrm{p} 11.2)$ contiguous gene syndromes by chromosome engineering in mice: phenotypic consequences of gene dosage imbalance. Mol Cell Biol 2003; 23: $3646-3655$.

32 Walz K, Spencer C, Kaasik K, Lee CC, Lupski JR, Paylor R: Behavioral characterization of mouse models for Smith-Magenis syndrome and dup(17)(p11.2p11.2). Hum Mol Genet 2004; 13: $367-378$.

33 Bi W, Yan J, Shi X et al: Rai1 deficiency in mice causes learning impairment and motor dysfunction, whereas Rai1 heterozygous mice display minimal behavioral phenotypes. Hum Mol Genet 2007; 16: 1802-1813.

34 Yan J, Keener VW, Bi W et al: Reduced penetrance of craniofacial anomalies as a function of deletion size and genetic background in a chromosome engineered partial mouse model for SmithMagenis syndrome. Hum Mol Genet 2004; 13: 2613-2624.
35 Balthasar N: Genetic dissection of neuronal pathways controlling energy homeostasis. Obesity (Silver Spring) 2006; 14 (Suppl 5): 222S-227S.

36 Accili D, Fishburn CS, Drago J et al: A targeted mutation of the D3 dopamine receptor gene is associated with hyperactivity in mice. Proc Natl Acad Sci USA 1996; 93: 1945-1949.

37 Kelly MA, Rubinstein M, Phillips TJ et al: Locomotor activity in D2 dopamine receptor-deficient mice is determined by gene dosage, genetic background, and developmental adaptations. J Neurosci 1998; 18: 3470-3479.

38 Dere E, De Souza-Silva MA, Frisch C et al: Connexin30-deficient mice show increased emotionality and decreased rearing activity in the open-field along with neurochemical changes. Eur $J$ Neurosci 2003; 18: 629-638.

39 Barinaga M: The cerebellum: movement coordinator or much more? Science 1996; 272: 482-483.

40 D'Hooge R, Hartmann D, Manil J, Colin F, Gieselmann V, De Deyn PP: Neuromotor alterations and cerebellar deficits in aged arylsulfatase A-deficient transgenic mice. Neurosci Lett 1999; 273: 93-96.

41 Hemsley KM, Hopwood JJ: Development of motor deficits in a murine model of mucopolysaccharidosis type IIIA (MPS-IIIA). Behav Brain Res 2005; 158: 191-199.

42 Costa AC, Walsh K, Davisson MT: Motor dysfunction in a mouse model for Down syndrome. Physiol Behav 1999; 68: 211-220.

43 Glynn D, Drew CJ, Reim K, Brose N, Morton AJ: Profound ataxia in complexin I knockout mice masks a complex phenotype that includes exploratory and habituation deficits. Hum Mol Genet 2005; 14: 2369-2385.

44 Ameye LG, Young MF: Animal models of osteoarthritis: lessons learned while seeking the 'Holy Grail'. Curr Opin Rheumatol 2006; 18: $537-547$.

45 Lin X, Cummings CJ, Zoghbi HY: Expanding our understanding of polyglutamine diseases through mouse models. Neuron 1999; 24: 499-502.

46 Hayes S, Turecki G, Brisebois $\mathrm{K}$ et al: CAG repeat length in RAI1 is associated with age at onset variability in spinocerebellar ataxia type 2 (SCA2). Hum Mol Genet 2000; 9: 1753-1758.

47 Zhang Z, Baldini A: In vivo response to high-resolution variation of Tbx1 mRNA dosage. Hum Mol Genet 2008; 17: 150-157.

Supplementary Information accompanies the paper on European Journal of Human Genetics website (http://www.nature.com/ejhg) 